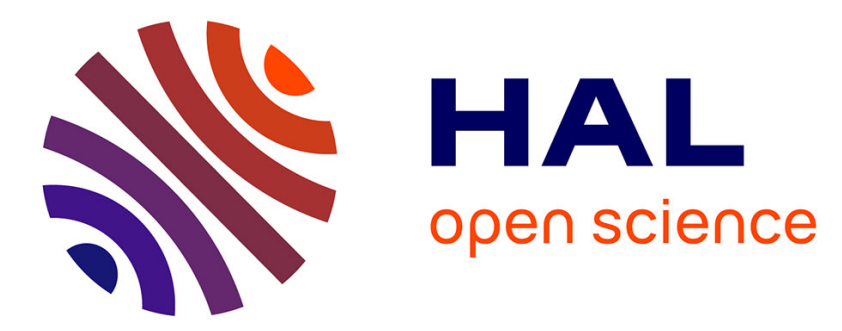

\title{
Microsatellite genotyping reveals diversity within populations of , the secondary symbiont of tsetse flies
}

Oumarou Farikou, Flobert Njiokou, Gérard Cuny, Anne Geiger

\section{To cite this version:}

Oumarou Farikou, Flobert Njiokou, Gérard Cuny, Anne Geiger. Microsatellite genotyping reveals diversity within populations of , the secondary symbiont of tsetse flies. Veterinary Microbiology, 2011, 150 (1-2), pp.207. 10.1016/j.vetmic.2011.01.021 . hal-00687331

\section{HAL Id: hal-00687331 \\ https://hal.science/hal-00687331}

Submitted on 13 Apr 2012

HAL is a multi-disciplinary open access archive for the deposit and dissemination of scientific research documents, whether they are published or not. The documents may come from teaching and research institutions in France or abroad, or from public or private research centers.
L'archive ouverte pluridisciplinaire HAL, est destinée au dépôt et à la diffusion de documents scientifiques de niveau recherche, publiés ou non, émanant des établissements d'enseignement et de recherche français ou étrangers, des laboratoires publics ou privés. 


\section{Accepted Manuscript}

Title: Microsatellite genotyping reveals diversity within populations of Sodalis glossinidius, the secondary symbiont of tsetse flies

Authors: Oumarou Farikou, Flobert Njiokou, Gérard Cuny, Anne Geiger

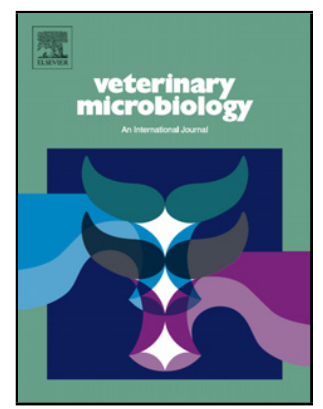

PII: S0378-1135(11)00040-X

DOI: doi:10.1016/j.vetmic.2011.01.021

Reference: VETMIC 5159

To appear in: $\quad$ VETMIC

Received date: $\quad 19-9-2010$

Revised date: $\quad 8-1-2011$

Accepted date: $\quad$ 24-1-2011

Please cite this article as: Farikou, O., Njiokou, F., Cuny, G., Geiger, A., Microsatellite genotyping reveals diversity within populations of Sodalis glossinidius, the secondary symbiont of tsetse flies, Veterinary Microbiology (2010), doi:10.1016/j.vetmic.2011.01.021

This is a PDF file of an unedited manuscript that has been accepted for publication. As a service to our customers we are providing this early version of the manuscript. The manuscript will undergo copyediting, typesetting, and review of the resulting proof before it is published in its final form. Please note that during the production process errors may be discovered which could affect the content, and all legal disclaimers that apply to the journal pertain. 
1 Short Communication

2

3 Microsatellite genotyping reveals diversity within populations of Sodalis

4 glossinidius, the secondary symbiont of tsetse flies

5

6 Running title: Sodalis glossinidius genotyping using microsatellite assay

7

8 Oumarou Farikou $^{\mathrm{a}, \mathrm{b}}$, Flobert Njiokou ${ }^{\mathrm{b}}$, Gérard Cuny ${ }^{\mathrm{a}}$ and Anne Geiger ${ }^{\mathrm{a}, *}$

9

a'UMR 177, IRD-CIRAD, CIRAD TA A-17/G, Campus International de Baillarguet, 34398

11 Montpellier Cedex 5, France

12 bniversity of Yaoundé I, Faculty of Science, BP 812, Yaoundé, Cameroon

13

14

15

16

$17 *$ Corresponding Author: Dr Anne Geiger

18 Address: UMR 177, IRD-CIRAD, CIRAD TA A-17/G, Campus International de Baillarguet,

1934398 Montpellier Cedex 5, France.

20 Phone: $+33(0) 467593925$

$21 \quad$ Fax: +33(0)4 67593894

22 E-mail: anne.geiger@ird.fr 


\section{Abstract}

\section{(26}

The aim of this study was to develop a PCR-based microsatellite genotyping method for identifying genetic diversity in Sodalis glossinidius, a symbiont associated with tsetse fly infection by trypanosomes causing human and animal trypanosomiasis. Allelic polymorphism at three loci, investigated on 40 fly gut extracts, evidenced eight alleles and the existence of five genotypes. This novel approach was shown to be efficient and suitable for routine largescale genotyping of $S$. glossinidius present in the biologically complex tsetse fly extracts; it could favor progress in the fields of diagnosis, epidemiology, population genetics, and fly/symbiont/trypanosome interactions.

5

(6)

7.

38

39

40

1

Keywords: Sodalis glossinidius, symbiont, microsatellites, genotyping, tsetse fly, Nagana, 49 sleeping sickness 


\section{Introduction}

Tsetse flies transmit trypanosomes responsible for human African trypanosomiasis (HAT) as well as the animal disease (Nagana). HAT affects a wide range of people in sub-Saharan Africa and is fatal if untreated, and Nagana is estimated to cost African agriculture US\$4.5 billion per year (Reinhardt, 2002). The available drugs are unsatisfactory (Barrett, 2006), while resistance is increasing (Matovu et al., 2001). Consequently, investigations for novel strategies must continue. Trypanosome transmission needs the parasite to establish in the tsetse fly midgut and to mature into an infective form before being transmitted to a novel mammalian host (Van den Abbeele et al., 1999). Tsetse flies harbor three different symbiotic bacteria among which Sodalis glossinidius is suspected of being involved in the fly's vector competence (Cheng and Aksoy, 1999; Dale and Welburn, 2001; Welburn and Maudlin, 1999). Recently, this bacterium was shown to be associated with infection of field populations of tsetse flies by trypanosomes (Farikou et al., 2010). Furthermore, genetic diversity was evidenced in $S$. glossinidius populations from insectary flies, suggesting that fly infection by trypanosomes could be favored by the presence of symbiont-specific genotype(s) (Geiger et al., 2007). Thus, a large-scale evaluation of the S. glossinidius genetic diversity in field populations of flies is needed. The AFLP technique previously used on DNA extracted from insectary fly hemolymph is not well adapted to routinely typing field samples because the hemolymph volume of such individual fly is too low, and the gut extracts, including the bacteria, are too complex. We therefore aimed to develop a Variable Number Tandem Repeat (VNTR) approach known to be highly discriminant (Le Flèche et al., 2006; Lindstedt, 2005; Whatmore et al., 2006). As the microsatellite approach has never been used to investigate the genetic diversity of $S$. glossinidius, we had to determine whether: a) it would be appropriate to distinguish genetically distinct Sodalis strains, b) the microsatellite approach could work on complex biological extract samples, and c) it would be suitable for routine analyses. 


\section{Materials and methods}

Glossina palpalis gambiensis individuals were chosen from flies that were field sampled in different areas of Burkina Faso. Pupae were collected from these flies. After adult emergence, the population was maintained in a level 2 containment insectary at $23^{\circ} \mathrm{C}$ and $80 \%$ relative humidity, without any selection. Individuals used in the present work were randomly chosen. The flies were dissected in a drop of sterile $0.9 \%$ saline solution. Midguts from each fly were then separately transferred into microfuge tubes containing ethanol $\left(95^{\circ}\right)$ for further symbiont analyses. The instruments were carefully cleaned after the dissection of each fly to prevent contamination. The microfuge tubes were stored at $-20^{\circ} \mathrm{C}$ until use.

DNA was extracted from midgut using the classical protocol (Navajas et al., 1998). Briefly, tissues were homogenized with a pestle in a cetyl trimethyl ammonium bromide (CTAB) buffer (CTAB 2\%; 0.1 M Tris, $\mathrm{pH} 8 ; 0.02 \mathrm{M}$ EDTA pH 8; $1.4 \mathrm{M} \mathrm{NaCl})$ and incubated at $60^{\circ} \mathrm{C}$ for $30 \mathrm{~min}$. The DNA was extracted from the lysis mixture with chloroform/isoamylic alcohol (24/1; V/V) and precipitated by adding isopropanol (V/V). After centrifugation $(10,000 \mathrm{~g}, 15 \mathrm{~min})$, the pellet was rinsed with $70 \%$ ethanol, air-dried, and resuspended in distilled sterile water. The DNA samples were stored at $-20^{\circ} \mathrm{C}$ until PCR amplification processing.

S. glossinidius microsatellite repeat sequences were selected in a data bank (GenBank, accession number AP008232) (Toh et al., 2006) using the Vector NTI software; primer pairs were designed for the sequences flanking such regions and tested to ensure that they specifically amplify S. glossinidius and not host DNA. Table 1 shows the primers selected to perform the present study.

One $\mu$ l of DNA was used for subsequent DNA amplification. Polymerase chain reactions (PCRs) were carried out using a DNA thermal cycler (PE Applied Biosystems, Foster City, CA, USA) in 20- $\mu$ l final volumes, containing 4 pmol of each primer, $0.2 \mathrm{mM}$ of each 
100 deoxyribonucleotide, $1 \mathrm{X}$ incubation buffer with $1.5 \mathrm{mM} \mathrm{MgCl} 2$ (Quantum Appligène, Ilkirch,

101 France) and 0.5 units of Taq DNA polymerase (Quantum Appligène). Samples were first

102

103

104

105

106

107

108

109 denatured at $94^{\circ} \mathrm{C}$ for 3 min and then processed through 40 cycles consisting in a denaturation step at $94^{\circ} \mathrm{C}$ for $30 \mathrm{~s}$, an annealing step at $55^{\circ} \mathrm{C}$ for $30 \mathrm{~s}$, and an extension step at $72^{\circ} \mathrm{C}$ for 1 min. The final elongation step was lengthened to $5 \mathrm{~min}$ at $72^{\circ} \mathrm{C}$. PCR products were checked by $2 \%$ agarose gel electrophoresis and visualized under UV light after ethidium bromide staining $(0.5 \mu \mathrm{g} / \mathrm{ml})$. Allele bands were then resolved in nondenaturing acrylamide gels (10\%), after loading 2-5 $\mu \mathrm{l}$ PCR products, and revealed by ethidium bromide staining.

In order to assess whether the amplicons actually corresponded to $S$. glossinidius microsatellites, bands representing the different alleles were purified using the Wizard DNA Clean Up System (Promega Corporation, Madison, WI, USA). Purified PCR fragments were cloned into pGEM-T Easy Vector (Promega Corporation). Clones of each cloned allele were purified with the Wizard Plus SV Minipreps DNA Purification System Kit (Promega, Charbonnière, France) and sequenced by GATC Biotech (Konstanz, Germany), allowing the allele size to be determined as well as the exact number of microsatellite repeats (GenBank accession numbers HQ842611-HQ842618).

(1) 


\section{Results}

126 Figure 1 shows an example of an electrophoretic separation on a 10\% polyacrylamide gel of

127 different alleles; it demonstrates the development of the experimental process to be 128 successful. Table 1 summarizes the characteristics of the three microsatellite markers selected

129 to investigate the polymorphism within the S. glossinidius samples from 40 G. palpalis

130 gambiensis flies, and to test the genotyping method: sequence of the repeats, part of the

131 flanking sequences used as primers, their location on the $S$. glossinidius genome, and finally

132 the number and size of the alleles evidenced at each locus. The repeat sequence of the ADNg

$1332 / 5$ marker is (AC). At this locus, two alleles that differ in the number of repeats, either five

134 or seven, were identified among the 40 samples; their size, including the flanking sequences,

135 was 176 and $180 \mathrm{bp}$, respectively. At the locus carrying the ADNg 21/22 marker, four alleles

136 were characterized that differ in the number of repeats, six, seven, nine, or 11, of the repeated

137 unit (GCC), and in their total length, 163, 166, 172, and $178 \mathrm{bp}$, respectively. Finally, two

138 alleles were identified at the $\mathrm{ADNg}$ 15/16 locus; they differed in the number, five or seven, of

139 their (AGG) unit repeat, and in their size, 106 or $112 \mathrm{bp}$. The combination of alleles amplified

140 at the three loci on each sample (fly midgut extract) characterizes the genotype of the Sodalis

141 strain the fly harbors. Significant diversity was evidenced among the $S$. glossinidius strains

142 from the 40 tsetse flies. Table 2 presents the combination of alleles, identified by their size

143 expressed as base pairs, for the 40 strains. Five allelic combinations, i.e., five genotypes, were

144 found, one of which was much more frequent (62.5\%) than the four others $(22.5,5,5$, and $5 \%$

145 respectively).

146

147

148

149 


\section{Discussion}

151 One of the challenges in the study of $S$. glossinidius is the difficulty encountered when

152 attempting to detect genetic diversity among strains. Previous studies have inferred 153 phylogenetic relatedness among strains based on similarity at the 16S rDNA gene (Aksoy et al., 1997). However, single-gene phylogenetics are unreliable for resolving close relationships (Baldo et al., 2006). As shown in the introduction, to progress in the understanding of the role played by the symbiont $S$. glossinidius in the tsetse's capacity to transmit trypanosomes, the availability of an efficient and accurate genotyping tool is needed; the previously used AFLP method (Geiger et al., 2007) is not well suitable for routine genotyping of symbiont populations from field flies: an alternative and effective new method had to be developed.

160 From a general point of view, it appears that the $S$. glossinidius developed microsatellite

161 method fulfils the performance criteria for a genotyping assay (Bricker and Ewalt, 2005), i.e.,

162 typing ability, reproducibility, stability, and discriminating power which is even better when

163 the investigation is extended to several loci. Substantial genetic diversity was therefore

164 observed among the 40 flies: eight alleles at the three loci investigated. These eight alleles

165 were shown to be combined differently in the 40 individuals and resulted in the identification

166 of five genotypes. It should be noted that the approach is actually quite appropriate to genetic

167 diversity analyses of microorganisms present in complex biological samples such as $S$.

168 glossinidius included in tsetse flies midgut extracts. It requires a small quantity of biological

169 material, and the alleles can be analyzed by simple polyacrylamide gel electrophoresis;

170 standardization and quality control are easy to achieve, and the recorded data can be easily

171 coded. The proposed technical approach will be useful for large scientific uses, genetic

172 population structure, epidemiology etc. It could possibly also be used for detecting mixed

173 infections: given that $S$. glossinidius is haploid, the detection of more than one band (one 
174 allele) at a given locus will mean that more than one $S$. glossinidius genotype is present in the

175 sample analyzed and the existence of a mixed infection can be assessed in the fly sampled.

176 To conclude, the microsatellite genotyping process we have adapted is an important tool for

177 routine and effective diagnosis of Sodalis strains and will advance the elucidation of the role

178 played by the symbiont in the vector competence of the tsetse fly, and finally in human and 179 animal trypanosomiasis.

180

181

182

183

184

185

186

187

188

189

190

191

192

193

194

195

196 


\section{Conflict of interest statement}

198 There is no conflict of interest with respect to funding or any other issue.

199

\section{Acknowledgments}

201 This study has been supported by the World Health Organization (WHO) and the 202 International Atomic Energy Agency (IAEA).

203 O. Farikou is a PhD student supported by the Institut de Recherche pour le Développement 204 (IRD).

205

206

207

208

209

210

211

212

213

214

215

216

217

218

219

9 


\section{References}

221 Aksoy, S., Chen, X., Hypsa, V., 1997. Phylogeny and potential transmission routes of midgut222 associated endosymbionts of tsetse (Diptera:Glossinidae). Insect Mol. Biol. 6, 183-90.

Baldo, L., Bordenstein, S., Wernegreen, J.J., Werren, J.H., 2006. Widespread recombination throughout Wolbachia genomes. Mol. Biol. Evol. 23, 437-449.

Barrett, MP., 2006. The rise and fall of sleeping sickness. Lancet. 367, 1377-1378.

Bricker, B.J., Ewalt, D.R., 2005. Evaluation of the HOOF-print assay for typing Brucella abortus strains isolated from cattle in the United States: results with four performance criteria. BMC Microbiol. 5, 37.

Cheng, Q., Aksoy, S., 1999. Tissue tropism, transmission and expression of foreign genes in vivo in midgut symbionts of tsetse flies. Insect Mol. Biol. 8, 125-132.

Dale, C., Welburn, SC., 2001. The endosymbionts of tsetse flies: manipulating host-parasite 237 interactions. Int. J. Parasitol. 31, 628-631.

239 Farikou, O., Njiokou, F., Mbida Mbida, JA., Njitchouang, GR., Djeunga, HN., Asonganyi, T., 240 Simarro, P.P., Cuny, G., Geiger, A., 2010. Tripartite interactions between tsetse flies, Sodalis 241 glossinidius and trypanosomes-an epidemiological approach in two historical human African 242 trypanosomiasis foci in Cameroon. Infect. Genet. Evol. 10, 115-21. 
243 Geiger, A., Ravel, S., Mateille, T., Janelle, J., Patrel, D., Cuny, G., Frutos, R., 2007. Vector

244 competence of Glossina palpalis gambiensis for Trypanosoma brucei s.l. and genetic

245 diversity of the symbiont Sodalis glossinidius. Mol. Biol. Evol. 24, 102-9.

247 Le Flèche, P., Jacques, I., Grayon, M., Al Dahouk, S., Bouchon, P., Denoeud, F., Nockler, K., 248 Neubauer, H., Guilloteau, L.A., Vergnaud, G., 2006. Evaluation and selection of tandem 249 repeat loci for a Brucella MLVA typing assay. BMC Microbiol. 6, 9.

Lindstedt, B.A., 2005. Multiple-locus variable number tandem repeats analysis for genetic fingerprinting of pathogenic bacteria. Electrophoresis 26, 2567-2582.

Matovu, E., Seebeck, T., Enyaru, JCK., Kaminsky, R., 2001. Drug resistance in Trypanosoma brucei spp., the causative agents of sleeping sickness in man and nagana in cattle. Microbes Infect. 3, 763-770.

Navajas, M., Lagnel, J., Gutierrez, J., Boursot, P., 1998. Species-wide homogeneity of nuclear 259 ribosomal ITS2 sequences in the spider mite Tetranychus urticae contrasts with extensive 260 mitochondrial COI polymorphism. Heredity. 80, 742-752.

262 Reinhardt, E., 2002. Travailler ensemble: la mouche tsé-tsé et la pauvreté rurale. [Internet]. 263 Available from: www.un.org/french/pubs/chronique/2002/numero2/0202p17_la_mouche_tse 264 tse.html. Chronique ONU, ONU Editor-September 02. 
266 Toh, H., Weiss, BL., Perkin, SAH., Yamashita, A., Oshima, K., Hattori, M., Aksoy, S., 2006.

267 Massive genome erosion and functional adaptations provide insights into the symbiotic 268 lifestyle of Sodalis glossinidius in the tsetse host. Genome Res. 16, 149-156.

270 Van den Abbeele, J., Claes, Y., Bockstaele, D., Ray, D., Coosemans, M., 1999. Trypanosoma 271 brucei spp. development in the tsetse fly: characterization of the post-mesocyclic stages in the 272 foregut and proboscis. Parasitology 118, 469-478.

273

274 Welburn, SC., Maudlin, I., 1999. Tsetse-trypanosome interactions: rites of passage. Parasitol. 275 Today $15,399-403$.

276

277 Whatmore, A.M., Shankster, S.J., Perrett, L.L., Murphy, T.J., Brew, S.D., Thirlwall, R.E., 278 Cutler, S.J., Macmillan, A.P., 2006. Identification and characterization of variable-number of 279 tandem-repeat markers for typing of Brucella spp. J. Clin. Microbiol. 44, 1982-1993. 
Figure legends

292

293 Figure 1. Example of fragment length polymorphism at the ADNg 21/22 locus in 18

294 Sodalis glossinidius samples.

295

296 The alleles have been separated by electrophoresis on a $10 \%$ polyacrylamide gel on the basis

297 of the size of their corresponding DNA sequence. Lane 1 corresponds to the "no template"

298 negative control. Lanes 2-19 correspond to S. glossinidius samples. Here three alleles have

299 been separated into three sizes: 163 (4 strains), 172 (13 strains), and 178 (1 strain) base pairs.

300

301

302

303

304

305

306

307

308

309

310

311

312

313

314

315

13 
Table 1. S. glossinidius microsatellite markers, PCR primers and allelic polymorphism

\begin{tabular}{|c|c|c|c|c|c|}
\hline Marker & $\begin{array}{l}\text { Repeat } \\
\text { sequence }^{\mathrm{a}}\end{array}$ & $\begin{array}{l}\text { Primer sequences } \\
\left(5^{\prime}-3^{\prime}\right)\end{array}$ & Location at $\mathrm{bp}^{\mathrm{b}}$ & $\begin{array}{l}\text { Number } \\
\text { of alleles }\end{array}$ & $\begin{array}{l}\text { Size of the } \\
\text { alleles (bp) }\end{array}$ \\
\hline \\
\hline $\operatorname{ADNg} 5 / 2$ & $(\mathrm{AC})_{\mathrm{x} 5,7}$ & GGCCGGTATTCTAACCGAC & $4115043-4115222$ & 2 & $176 / 180$ \\
\hline & & AACTGCCAGGCATCCATTAC & & & \\
\hline ADNg 21/22 & $(\mathrm{GCC})_{\mathrm{x}} 6,7,9,11$ & GAGCAAATCTCCCAGCACAT & $1450588-1450759$ & 4 & $163 / 166 / 172 / 178$ \\
\hline & & TTCTTGTCCCTCAACCCATC & & & \\
\hline $\mathrm{ADNg} 15 / 16$ & $(\mathrm{AGG})_{\mathrm{x} 5,7}$ & ATACGGCGAAGCAATGAGAC & $3250160-3250283$ & 2 & $106 / 112$ \\
\hline & & CAGCCTCTAAGCGCTCAACTC & & & \\
\hline
\end{tabular}

$13{ }^{\mathrm{a}}$ and number of repeats recorded at each locus ( 5 or 7 at $\mathrm{ADNg} 5 / 2$, etc); ${ }^{\mathrm{b}} \mathrm{GenBank}$ accession number AP008232 
1 Table 2. Combinations of three alleles, one from each of the three loci, recorded among

2 the 40 S. glossinidius strains sampled; number and percentage of strains carrying each

3 combination

4

5

$6 \quad \operatorname{ADNg} 2 / 5$

ADNg 21/22

ADNg 15/16

Number and (\%)

7

of strains

$-8$

9180 *

172

112

$25(62.5 \%)$

$10 \quad 176$

163

112

$9(22.5 \%)$

$11 \quad 180$

178

112

$2(5 \%)$

$12 \quad 180$

166

112

$2(5 \%)$

13

176

163

106

$2(5 \%)$

14

15 *alleles identified by their size (number of base pairs) - see also Table 1 for details 


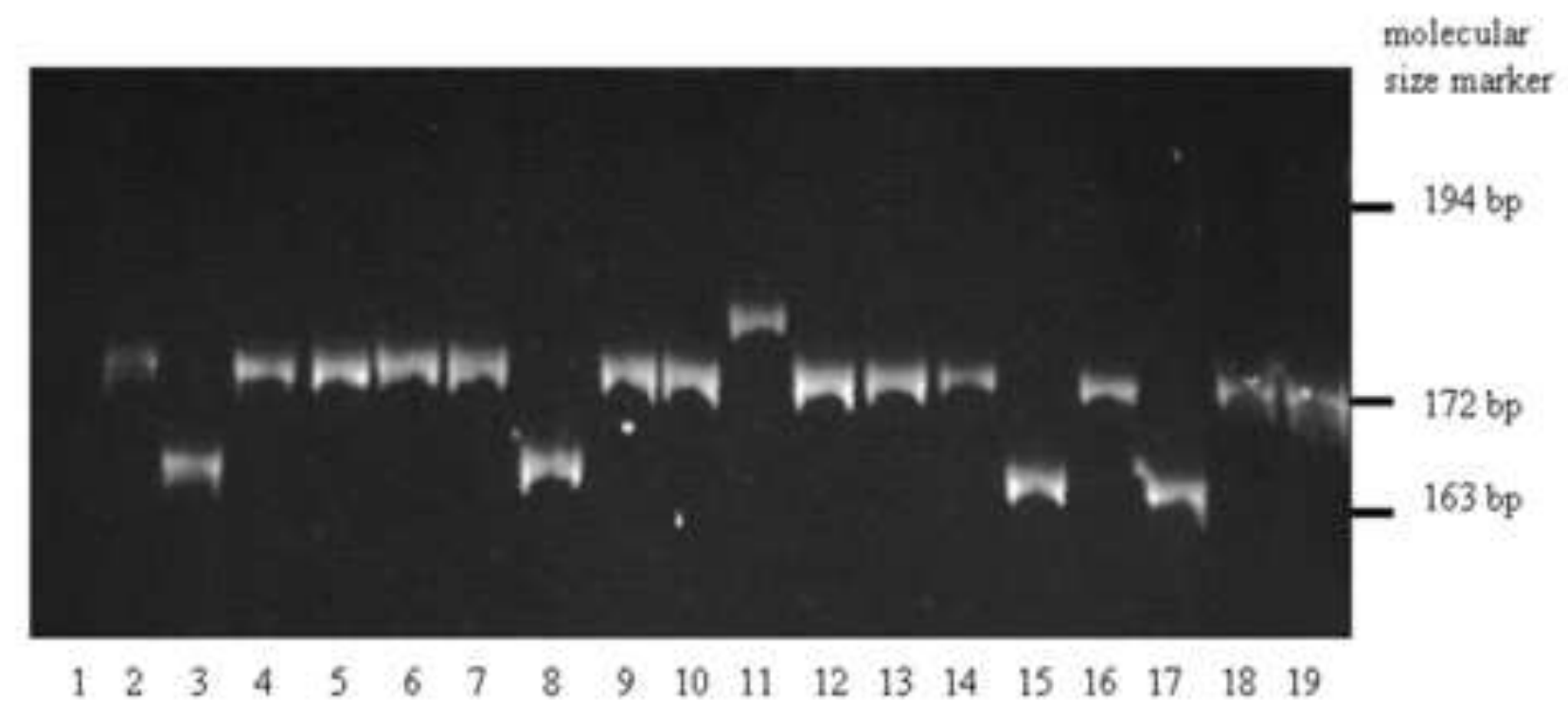

Figure 1

(1)

$\begin{array}{lllllllllllllllllll}1 & 2 & 3 & 4 & 5 & 6 & 7 & 8 & 9 & 10 & 11 & 12 & 13 & 14 & 15 & 16 & 17 & 18 & 19\end{array}$

(1)

(1)

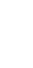

\section{rare}

